\title{
Universiteit
}

Leiden

The Netherlands

\section{Autobiographical memory in the euthymic phase of recurrent depression}

Spinhoven, P.; Bockting, C.L.H.; Schene, A.H.; Koeter, M.W.J.; Wekking, E.M.; Williams, J.M.G.

\section{Citation}

Spinhoven, P., Bockting, C. L. H., Schene, A. H., Koeter, M. W. J., Wekking, E. M., \& Williams, J. M. G. (2006). Autobiographical memory in the euthymic phase of recurrent depression. Journal Of Abnormal Psychology, 115, 590-600. Retrieved from https://hdl.handle.net/1887/13190

Version: $\quad$ Not Applicable (or Unknown)

License: $\quad$ Leiden University Non-exclusive license

Downloaded from: https://hdl.handle.net/1887/13190

Note: To cite this publication please use the final published version (if applicable). 


\title{
Autobiographical Memory in the Euthymic Phase of Recurrent Depression
}

\author{
Philip Spinhoven \\ Leiden University
}

\author{
Elizabeth M. Wekking \\ Leiden University and University of Amsterdam
}

\author{
Claudi L. H. Bockting, Aart H. Schene, and \\ Maarten W. J. Koeter \\ University of Amsterdam
}

J. Mark G. Williams
Oxford University

\author{
The DELTA Study Group \\ University of Amsterdam
}

\begin{abstract}
The authors investigated autobiographical memory specificity in subjects who formerly had depression. In 122 euthymic patients with at least two previous major depressive episodes, memory specificity was significantly impaired compared to matched control participants but not related to residual symptoms and illness characteristics, was not differentially affected by cognitive therapy, and was also not predictive of relapse/recurrence during the 2-year follow-up. However, memory specificity was associated with age, education, and immediate and delayed memory recall. The results suggest that memory specificity may reflect a global cognitive impairment that remains in patients who (formerly) had depression but does not constitute a trait marker for vulnerability for relapse/recurrence.
\end{abstract}

Keywords: autobiographical memory, depression, relapse/recurrence, cognitive therapy, executive functioning

Autobiographical memory can be seen as a type of declarative memory (Squire, 1995) and more specifically as a form of

Philip Spinhoven, Departments of Psychology and Psychiatry, Leiden University, Leiden, the Netherlands; Claudi L. H. Bockting, Aart H. Schene, Maarten W. J. Koeter, and the DELTA Study Group, Department of Psychiatry, Academic Medical Center, University of Amsterdam, Amsterdam, the Netherlands; Elizabeth M. Wekking, Department of Psychology, Leiden University, Leiden, the Netherlands, and Department of Psychiatry, Academic Medical Center, University of Amsterdam, Amsterdam, the Netherlands; J. Mark G. Williams, Department of Psychiatry, Oxford University, Oxford, England.

This study was supported by grants from the Health Research Development Counsel (ZON), the Department Prevention Program, and the National Foundation for Mental Health (NFGV).

We are most grateful to the participants in our study. In addition, we express our appreciation to the staff at the participating psychiatric sites for their recruitment efforts and to the following therapists for conducting the cognitive therapy: Willemijn Scholten, Swanny Wierenga, Mieke van der Rijken, Ruud Kol, Birgitta Schalken, Els Loeb, Vera van der Kraan, and Annemarie Fouwels. We also thank our interviewers and independent raters and specifically Irene Visch for assistance with data management and support and Anoek Maan for assistance with data analysis. Finally, we thank Ismay Kremers and Rimke Haringsma for collecting the Autobiographical Memory Test (AMT) data in control subjects and Chantal van Duyn, Kim Beukenhorst, and Martin de Pruyssenaere for scoring the AMT data. The following colleagues contributed to the DELTA study: Hanneke Assies, Claudi Bockting, Jochanan Huyser, Maarten Koeter, Anja Lok, Guido Nabarro, Aart Schene, Philip Spinhoven, Ieke Visser, Elly Wekking, and Luuk Wouters.

Correspondence concerning this article should be addressed to Philip Spinhoven, Department of Psychology, Leiden University, Wassenaarseweg 52, 2333 AK Leiden, the Netherlands. E-mail: spinhoven@ fsw.leidenuniv.nl episodic memory (Tulving, 1972). Autobiographical memory will be defined here as declarative, explicit memory for a specific event in time and place with experiential awareness of self in the experience ("autonoesis") (Wheeler, Stuss, \& Tulving, 1997). It has been found that autobiographical memory performance in patients with a depressive disorder is impaired in comparison to control individuals without depression. More specifically, patients with depression are characterized by an inability to recall specific individually experienced events and answer with overgeneral or categoric descriptions of situations instead (see van Vreeswijk \& de Wilde, 2004; Williams, 1995, for a meta-analysis or review of studies).

Up till now only a few relatively small studies have assessed autobiographical memory performance in patients in remission from recurrent depression in comparison with patients with depression (Nandrino, Pezard, Poste, Reveillere, \& Beaune, 2002; Park, Goodyer, \& Teasdale, 2002) or normal control subjects (Mackinger, Pachinger, Leibetseder, \& Fartacek, 2000; Park et al., 2002). The study results suggest that autobiographical memory impairment persists after recovery and is also characteristic of patients in remission.

Because it is rather uncommon to find a cognitive marker for vulnerability for depression without stress/mood induction, it seems worthwhile to replicate these findings in a larger and more representative group of euthymic patients with recurrent depression. Such a replication would have potential clinical significance. Although it is possible that autobiographical memory impairment only represents a cognitive epiphenomenon associated with past or present depression, there are some data suggesting that it may constitute a factor involved in the onset 
or recurrence of a depressive episode. In several studies it has been found that autobiographical memory impairment is associated with poor problem-solving skills (e.g., Goddard, Dritschel, \& Burton, 1996) and also with difficulties in imagining specific situations in the future (e.g., Williams et al., 1996). It is conceivable that in daily life situations stressful events or mood changes will more easily induce a depressive episode when these cognitive coping skills are impaired. Evidence for an association of lack of memory specificity with known clinical predictors of relapse/recurrence (such as number of prior depressive episodes, residual or subthreshold symptoms, age of onset, and months of recovery since the last episode; Ormel, Oldehinkel, \& Vollebergh, 2004) would yield support for the supposition that autobiographical memory specificity constitutes a mechanism involved in mediating relapse/recurrence in patients with recurrent depression.

Another question in need of further exploration is whether autobiographical memory impairment reflects a broader deficit in cognitive functioning. Such an association has been studied in older people (Phillips \& Williams, 1997; Sampson, Kinderman, Watts, \& Sembi, 2003), adolescents with major depression (de Decker, Hermans, Raes, \& Eelen, 2003; Park et al., 2002), patients with traumatic brain injury (Williams, Williams, \& Ghadiali, 1998), patients with a borderline personality disorder (Arntz, Meeren, \& Wessel, 2002), and normal individuals (Williams \& Dritschel, 1992). In most of these studies, a moderately strong relationship of memory specificity with general cognitive abilities (e.g., semantic fluency) and memory functioning (e.g., immediate and delayed recall of verbal material) has been found. Because memory impairment is consistently found in individuals with clinical depression versus those without depression (Burt, Zembar, \& Niederehe, 1995) and seems to remain stable over time (Paradiso, Lamberty, Garvey, \& Robinson, 1997), it is especially worthwhile to investigate whether overgeneral autobiographical memory in patients who formerly had depression reflects a broader deficit in executive control or memory retrieval.

In summary, the first part of the present study was crosssectional, and we investigated whether specificity of autobiographical memory in euthymic patients with recurrent depression in the past is impaired in comparison with healthy control individuals without depression. It was hypothesized that specificity of autobiographical memory in this group would be lower than that of normal control individuals. Moreover, the association of autobiographical memory specificity with clinical variables predictive of relapse/recurrence was investigated. It was hypothesized that reduced levels of memory specificity would be found especially in patients with a higher number of previous depressive episodes. Finally, we also investigated whether lack of memory specificity reflected a more global cognitive impairment as often found in patients who (formerly) had depression. It was predicted that reduced memory specificity would be especially associated with impairments in memory retrieval. In the second part of the study, a prospective study that assessed the effect of group cognitive therapy on memory specificity and the predictive value of memory specificity on relapse/recurrence is described.

\section{Part 1}

\section{Method}

\section{Participants}

Participants were recruited as part of a randomized, controlled trial of the preventive effect of a group cognitive therapy on relapse/recurrence of depression in a group of patients at high risk for recurrence in comparison with treatment as usual (Bockting et al., 2005). To be eligible individuals had to meet the following criteria: (a) at least two major depressive episodes in the last 5 years, as defined according to the Diagnostic and Statistical Manual of Mental Disorders (4th ed.; DSM-IV; American Psychiatric Association, 1994) and assessed by the Structured Clinical Interview for DSM-IV (SCID-I; First, Spitzer, Gibbon, \& Williams, 1997) by trained evaluators; (b) current remission status, according to $D S M-I V$ criteria, for longer than 10 weeks and no longer than 2 years ago; (c) a current score on the Hamilton Rating Scale for Depression (Hamilton, $1960)$ of $<10$. Exclusion criteria were current mania or hypomania or a history of bipolar illness, any psychotic disorder (current and previous), organic brain damage, current alcohol or drug abuse or dependence, predominant anxiety disorder, recent electroconvulsive therapy, recent cognitive treatment or receiving cognitive therapy at the start of the study, or current psychotherapy with a frequency of more than 2 times a month. There was no restriction in using pharmacotherapy.

Clinical participants were recruited at psychiatric centers and through media announcement in the Netherlands. After complete description of the study to the subjects, written informed consent was obtained before randomization. The protocol was approved by the institutional ethics review committees.

The healthy control group was recruited through advertisements in a local newspaper, in community centers, and on the Internet. Participants with a $D S M-I V$ Axis I disorder as determined by a shortened version of the SCID-I, the Mini International Neuropsychiatric Interview (MINI; Sheehan et al., 1998), or a previous depressive episode were excluded. Moreover, because trauma exposure may be associated with memory specificity (Hermans et al., 2004) participants reporting severe childhood sexual or physical abuse were also excluded. Control participants were comparable with the clinical participants on age, education level, and gender ratio (see Results section).

\section{Measures}

Autobiographical Memory Test (AMT). McNally, Lasko, Macklin, and Pitman (1995) modified the autobiographical memory paradigm, which was used by Williams and Broadbent (1986). In this modified version, respondents are asked to mention a specific moment at which they exhibited a trait that is written on a card (e.g., "guilty" or "helpful"). A specific memory is defined as a memory that refers to a particular event in the past that happened on one particular day, lasting no longer than 1 day. At study entry the following positive $(+)$ and negative $(-)$ words were presented: friendly $(+)$, guilty $(-)$, impolite $(-)$, honest $(+)$, helpful $(+)$, jealous $(-)$, intelligent $(+)$, selfish $(-)$, humorous $(+)$, and hostile $(-)$. Words were read aloud and at the same time were shown on a card. The cue words were presented after three practice words. The task was started only after it was clear during the practice phase that the respondent understood the purpose of the task. Respondents were allowed 60 seconds to remember an event and if they did not recall one, the next word was presented.

Answers were recorded on audiotape. The following scoring categories were used: (a) specific, (b) categoric, (c) extended, and (d) no memory/ omission. Category (a) was scored when the respondent's first memory referred to a particular event on one particular day. Category (b) was scored when the memory referred to repeated events. Category (c) was scored when the remembered event lasted longer than 1 day. Category (d) was scored when the respondent did not mention a memory or did not respond. One trained research assistant who was blind for treatment condition 
scored all the tapes. Interrater agreement on about $50 \%$ of the retrieved memories $(n=610)$ indicated good reliability, $87.8 \%$ agreement, $\kappa=$ 0.77 , comparable with previous studies. ${ }^{1}$

Severity of depressive symptoms. The 17-item Hamilton Rating Scale for Depression (HRSD; Hamilton, 1960) and the 21-item Beck Depression Inventory (BDI; Beck, Rush, Shaw, \& Emery, 1979) were used to assess patients' levels of depressive symptomatology.

Neuropsychological measures. The Stroop Color-Word Test (Hammes, 1978) consists of three separate trials (reading color words, naming colors, and naming the print of the color words, disregarding their verbal content). In this third trial, the decrease in color-naming speed when presented with colored words in nonmatching colored inks as compared with the colornaming condition is called the color-word interference effect and is considered to be a measure of selective attention. The Digit Span test is a subtest of the Wechsler Adult Intelligence Scale (Wechsler, 1981). The subtest consists of two parts and requires the subject to repeat digits forward and backward. The test is considered to be a measure of immediate memory (forward) and working memory (backward). The Story Recall (logical memory) subtest of the Rivermead Behavioral Memory Tests (RBMT; Wilson, Cockburn, \& Baddeley, 1985) aims to detect impairment of everyday memory functioning by mimicking the demands made on memory by normal daily life. The subject is asked to remember a short passage, and the task consists of both an immediate and delayed recall component. The California Verbal Learning Test (CVLT; Delis, Kramer, Kaplan, \& Ober, 1987) assesses multiple aspects of verbal learning by the use of two shopping lists presented as the "Monday" and "Tuesday" list. The CVLT measures, among other things, immediate and delayed recall 20 minutes after presentation of the word list. The selected tests are internationally accepted (Lezak, Howieson, \& Lorin, 2004) and frequently used in clinical neuropsychological studies measuring attention and memory.

\section{Procedure}

After telephone screening on inclusion and exclusion criteria, patients were administered the SCID-I and HRSD. Patients who met inclusion criteria and no exclusion criteria were tested before random assignment to treatment condition and the start of therapy. Participants completed first the AMT and were subsequently neuropsychologically tested. After the purpose and procedures of the study were explained by phone, control participants were invited for a single assessment session. Participants who did not meet exclusion criteria as assessed by the MINI and some additional questions on previous trauma and previous depressive episodes subsequently completed the AMT.

\section{Results}

\section{Participant Characteristics}

A total of 122 clinical subjects completed the assessment battery. The mean age of the patients was 44.7 years $(S D=9.0)$, and $75.4 \%$ of the sample were women. Nineteen percent of the subjects reported two previous depressive episodes in the past, $25.9 \%$ reported three previous episodes, $27.6 \%$ reported four to six previous episodes, and $27.6 \%$ reported six or more previous episodes. The prevalence of Axis I disorders in this euthymic group of patients was quite low [one or more psychiatric disorders as assessed with the SCID-I (First et al., 1997) were seen in 12.3\% of the patients: social phobia $(n=7)$, panic disorder $(n=4)$, eating disorder $(n=3)$, posttraumatic stress disorder $(n=1)$, obsessivecompulsive disorder $(n=1)$, generalized anxiety disorder $(n=1)$, and specific phobia $(n=1)]$. The control group consisted of 37 participants and did not differ from the clinical group with respect to age, education level, and gender ratio (see Table 1).

\section{Differences in Number of Specific Memories Between Euthymic Patients and Normal Control Participants}

To investigate whether euthymic patients and normal control participants produced different numbers of specific memories and whether there was a different response pattern to positive and negative cue words, a mixed-model $2 \times 2$ analysis of variance was conducted with Group (euthymic or normal) as the betweensubjects variable and Cue Type (positive or negative) as a withinsubjects variable. Age and level of education were entered as covariates. Only a significant main effect for group was found, $F(1,155)=11,628, p<.001$. Euthymic patients who previously had depression reported significantly fewer specific memories $(M=5.3 ; S D=2.8)$ than normal control participants $(M=7.3$; $S D=1.8$ ) irrespective of cue type (see Table 1). Although adjusted mean scores were used in the statistical analyses, the values of nonadjusted mean scores for memory specificity are presented in the text and Table 1 for the sake of comparison with results of previous studies on this topic. No further significant main or interaction effects were found.

\section{Relationships of Specific Memories With Demographic and Clinical Variables}

In the clinical group, the association of specificity of autobiographical memory with demographic and clinical risk factors was further assessed with $t$ tests for independent groups, analysis of variance, or Pearson correlation coefficients if appropriate (see Table 2). Of the demographic variables only age and level of education were significantly correlated with the number of specific (positive and negative) autobiographical memories with younger and higher educated patients retrieving more specific memories. Of the clinical risk factors (i.e., BDI and HRSD scores, age of first onset, duration of illness, number of previous depressive episodes, duration of last depressive episode, months of recovery since last depressive episode, use of antidepressants (yes/no), and type of current treatment), none was significantly correlated with memory specificity.

\section{Relationship of Specific Memories With Neuropsychological Measures}

In the clinical group the association of specificity of autobiographical memory with various neuropsychological measures was assessed with Pearson correlation coefficients (see Table 3). As can be seen, the number of specific (positive and negative) memories showed a significant and positive relationship with scores for

\footnotetext{
${ }^{1}$ In the present study the number of specific memories in response to positive or negative cues on the AMT was used to operationalize memory specificity. This method of scoring is in accordance with most studies conducted up to now (see van Vreeswijk et al., 2004, for a review). Analyzing the results of the present study with the percentage of specific positive or negative memories, taking into account the number of omissions or the number of times subjects did not comply with the task, essentially yielded the same results. Moreover, on the basis of coding autobiographical memories in response to positive or negative cues on the AMT as categoric or not, a comparable pattern of results was obtained, suggesting that a reduced number of specific memories and an increased number of categoric memories are functionally equivalent.
} 
Table 1

Demographic Data and Number of Specific Memories on the AMT in Euthymic $(n=122)$ and Healthy Control Subjects $(n=37)$

\begin{tabular}{|c|c|c|c|c|c|c|}
\hline \multirow[b]{2}{*}{ Variable } & \multicolumn{2}{|c|}{$\begin{array}{l}\text { Euthymic } \\
\text { subjects }\end{array}$} & \multicolumn{2}{|c|}{$\begin{array}{l}\text { Normal control } \\
\text { subjects }\end{array}$} & \multirow[b]{2}{*}{$t$} & \multirow[b]{2}{*}{$p$} \\
\hline & $M$ & $S D$ & $M$ & $S D$ & & \\
\hline Age (years) & 44.7 & 9.0 & 44.2 & 13.3 & .194 & $n s$ \\
\hline Specific memories & 5.3 & 2.8 & 7.3 & 1.8 & 5.048 & $<.001$ \\
\hline Specific positive memories & 2.7 & 1.6 & 3.7 & 1.2 & 4.271 & $<.001$ \\
\hline Specific negative memories & 2.7 & 1.5 & 3.6 & 1.1 & 4.065 & $<.001$ \\
\hline Gender $(\%)$ & & & & & $.138^{\mathrm{a}}$ & $n s$ \\
\hline Male & \multicolumn{2}{|c|}{24.6} & \multicolumn{2}{|c|}{21.6} & & \\
\hline Female & \multicolumn{2}{|c|}{75.4} & \multicolumn{2}{|c|}{78.4} & & \\
\hline Education $(\%)^{\mathrm{b}}$ & & & & & $4.177^{\mathrm{a}}$ & $n s$ \\
\hline Low & \multicolumn{2}{|c|}{13.5} & \multicolumn{2}{|c|}{29.3} & & \\
\hline Medium & \multicolumn{2}{|c|}{35.1} & \multicolumn{2}{|c|}{33.6} & & \\
\hline High & \multicolumn{2}{|c|}{51.4} & \multicolumn{2}{|c|}{37.1} & & \\
\hline
\end{tabular}

Note. $\quad$ AMT $=$ Autobiographical Memory Test.

${ }^{a}$ Chi-square value. ${ }^{\mathrm{b}}$ Education level was divided in three categories with respect to the Dutch educational system.

both immediate recall and delayed recall as measured with the RBMT and CVLT. Scores for focused attention (Stroop ColorWord Test), immediate memory for abstract digits (Digit Span: Forwards) and working memory (Digit Span: Backwards) were not significantly associated with scores for memory specificity.

Next, partial correlation coefficients were calculated to remove the correlation that is due to their mutual association with the use of antidepressants (coded as a dummy variable 0/1) and the severity of residual depressive complaints (BDI and HRSD scores) as possible confounding factors. Results showed that all significant and positive relationships between neuropsychological measurements and number of specific (positive and negative) memories were retained. Moreover, partial correlations were calculated to investigate whether the association of RBMT and CVLT scores with the number of specific (positive and negative) memories was accounted for by age and education level. These analyses showed that the total number of specific memories and the total number of specific negative memories remained significantly and positively correlated with immediate and delayed recall as measured with the RBMT and CVLT.

\section{Discussion}

Part 1 had three aims and each of these is considered in turn in the light of the results. The first aim was to test the hypothesis that the memory specificity of euthymic patients with recurrent depressive episodes would be lower than that of normal control participants. The results supported this hypothesis even after statistically correcting for age and level of education. Moreover, the mean number of specific autobiographical memories $(M=5.3 ; S D=2.8)$ is very comparable to that of inpatients with depression $(M=5.2 ; S D=2.2)$ (Hermans et al., 2004) and outpatients with depression $(M=5.4$; $S D=2.6)$ (Kremers, Spinhoven, \& Van der Does, 2004). These data suggest that autobiographical memory impairment is not a cognitive epiphenomenon of a depressed state and is a characteristic of patients in remission.
The second aim of the study was to investigate the association of autobiographical memory impairment with several clinical risk factors for relapse/recurrence. Contrary to our expectations, none of the relationships with clinical characteristics proved to be significant. Because only euthymic patients with at least two depressive episodes were included, we cannot exclude the possibility that different results would have been obtained in patients in remission from a first episode. Results of the studies of Park et al. (2002) in adolescents with a first depressive episode indicate, however, that already after a first depressive episode memory specificity in patients in remission is comparable to that of adolescents with depression (however, see Nandrino et al., 2002, for slightly different findings). Taken together, our results seem to imply that although autobiographical memory impairment can be observed in patients in remission, it is not associated with known clinical risk factors for relapse/recurrence, such as number of previous episodes and level of residual depressive symptoms.

The relationship of autobiographical memory with general cognitive abilities and other memory tests was also explored. Comparable with most previous studies, a moderately strong association of memory specificity with education as a proxy for intelligence (Arntz et al., 2002; de Decker et al., 2003; Wessel, Meeren, Peeters, Arntz, \& Merckelbach, 2001) was found. These results concur with those of previous studies showing a consistent association of memory specificity with general intelligence (Park et al., 2002; Sampson et al., 2003; Wessel, Merckelbach, \& Dekkers, 2002; Williams et al., 1998). Moreover, a relationship was observed with indices of immediate and delayed memory retrieval, which remained significant over and above the effect of age, educational level, use of antidepressants, and level of residual depressive symptoms on autobiographical memory. These findings are in agreement with results of other studies (Phillips \& Williams, 1997; Williams et al., 1998; Winthorpe \& Rabbitt, 1988), indicating that indices for executive functioning and memory recall are related to autobiographical memory specificity independent of age and gen- 
Table 2

Relationship of Demographic and Clinical Variables With Number of Specific Memories on the AMT $(n=122)$

\begin{tabular}{|c|c|c|c|c|c|c|c|}
\hline Variable & $M$ & $S D$ & $\begin{array}{c}\text { Specific } \\
\text { memories }(r)\end{array}$ & \multicolumn{2}{|c|}{$\begin{array}{l}\text { Specific positive } \\
\text { memories }(r)\end{array}$} & \multicolumn{2}{|c|}{$\begin{array}{l}\text { Specific negative } \\
\text { memories }(r)\end{array}$} \\
\hline Age (years) & 44.7 & 9.0 & $-.25 * *$ & \multicolumn{2}{|c|}{$-.23 *$} & \multicolumn{2}{|c|}{$-.21 *$} \\
\hline Level of education (0-6) & 3.4 & 1.6 & $.28 * *$ & \multicolumn{2}{|c|}{$.20 *$} & \multicolumn{2}{|c|}{$.30 * * *$} \\
\hline BDI & 11.8 & 7.5 & .01 & \multicolumn{2}{|c|}{-.03} & \multicolumn{2}{|c|}{.05} \\
\hline HRSD & 3.6 & 2.8 & .03 & \multicolumn{2}{|c|}{.03} & \multicolumn{2}{|c|}{.02} \\
\hline Age of first onset & 27.5 & 12.2 & .16 & \multicolumn{2}{|c|}{-.17} & \multicolumn{2}{|c|}{-.12} \\
\hline Duration of illness (years) & 17.2 & & .02 & \multirow{2}{*}{\multicolumn{2}{|c|}{$\begin{array}{l}.01 \\
.01\end{array}$}} & \multirow{2}{*}{\multicolumn{2}{|c|}{$\begin{array}{r}-.04 \\
.02\end{array}$}} \\
\hline \multirow[t]{2}{*}{ Months since last episode } & 8.7 & 6.3 & .01 & & & & \\
\hline & $\%$ & $M$ & $S D$ & $M$ & $S D$ & $M$ & $S D$ \\
\hline \multicolumn{8}{|l|}{ Gender } \\
\hline Male & 24.6 & 6.2 & 2.6 & 2.9 & 1.6 & 3.2 & 1.3 \\
\hline Female & 75.4 & 5.1 & 2.8 & 2.6 & 1.6 & 2.5 & 1.5 \\
\hline \multicolumn{8}{|l|}{ Previous episodes } \\
\hline 2 episodes & 19.0 & 5.0 & 2.9 & 2.4 & 1.7 & 2.4 & 1.6 \\
\hline 3 episodes & 25.9 & 5.0 & 3.1 & 2.7 & 1.7 & 2.3 & 1.6 \\
\hline 4-6 episodes & 27.6 & 5.9 & 2.7 & 2.8 & 1.6 & 3.1 & 1.4 \\
\hline$>6$ episodes & 27.6 & 5.3 & 2.5 & 2.8 & 1.5 & 2.5 & 1.4 \\
\hline \multicolumn{8}{|l|}{ Duration last episode } \\
\hline$<2$ months & 28.4 & 5.4 & 2.8 & 2.5 & 1.6 & 2.4 & 1.5 \\
\hline$>2$ and $<8$ months & 45.7 & 4.8 & 2.7 & 2.4 & 1.5 & 2.3 & 1.6 \\
\hline$>8$ months & 25.9 & 5.9 & 2.7 & 3.2 & 1.7 & 2.7 & 1.3 \\
\hline \multicolumn{8}{|l|}{ Antidepressants } \\
\hline Yes & 53.3 & 5.4 & 2.8 & 2.7 & 1.7 & 2.7 & 1.5 \\
\hline No & 46.7 & 5.2 & 2.8 & 2.6 & 1.6 & 2.6 & 1.5 \\
\hline \multicolumn{8}{|l|}{ Current treatment } \\
\hline Family doctor & 24.6 & 4.9 & 2.8 & 2.4 & 1.7 & 2.5 & 1.5 \\
\hline Psychiatric help & 33.1 & 5.7 & 2.8 & 3.9 & 1.7 & 2.5 & 1.4 \\
\hline No treatment & 44.3 & 5.3 & 2.8 & 2.6 & 1.6 & 2.7 & 1.5 \\
\hline
\end{tabular}

Note. $\quad \mathrm{AMT}=$ Autobiographical Memory Test $; \mathrm{BDI}=$ Beck Depression Inventory; HRSD $=$ Hamilton Rating Scale for Depression.

$* p<.05 . \quad * * p<.01 . \quad * * * p<.001$.

eral intelligence (but see Wessel et al., 2002, for contradictory results), which suggests that impaired memory specificity can be partly accounted for by a more general neurocognitive deficit of patients with previous depression as was also suggested by some authors (Paradiso et al., 1997).

\section{Part 2}

Brittlebank, Scott, Williams, and Ferrier. (1993) were the first to demonstrate that in a group of depressed psychiatric inpatients those patients with higher levels of autobiographical memory

Table 3

Neuropsychological Measures and Pearson's Correlation Coefficients With Number of Specific Memories on the AMT $(n=122)$

\begin{tabular}{lccccc}
\hline \multicolumn{1}{c}{ Variable } & $M$ & $S D$ & $\begin{array}{c}\text { Specific } \\
\text { memories }(r)\end{array}$ & $\begin{array}{c}\text { Specific positive } \\
\text { memories }(r)\end{array}$ & $\begin{array}{c}\text { Specific negative } \\
\text { memories }(r)\end{array}$ \\
\hline $\begin{array}{l}\text { Stroop: Selective attention } \\
\text { Digit Span (WAIS) }\end{array}$ & 35.1 & 16.7 & -.08 & -.12 & -.02 \\
$\quad$ Forwards & 5.7 & 1.0 & .10 & .10 & .08 \\
$\quad$ Backwards & 4.5 & 0.9 & .17 & .14 & .16 \\
$\begin{array}{l}\text { Story Recall (RBMT) } \\
\quad \text { Immediate recall }\end{array}$ & 16.6 & 6.1 & $.32^{* * *}$ & $.21^{*}$ & $.38^{* * * *}$ \\
$\quad$ Delayed recall & 13.3 & 6.0 & $.30^{* * *}$ & $.18^{*}$ & $.36^{* * *}$ \\
$\quad \begin{array}{l}\text { Shopping list (CVLT) } \\
\quad \text { Immediate recall }\end{array}$ & 11.1 & 3.1 & $.28^{* * *}$ & $.10^{*}$ & $.33^{* * * *}$ \\
$\quad$ Delayed recall & 11.7 & 3.0 & $.20^{* * *}$ & $.29^{* *}$ \\
\hline
\end{tabular}

Note. $\quad$ AMT $=$ Autobiographical Memory Test; WAIS $=$ Wechsler Adult Intelligence Scale; RBMT = Rivermead Behavioral Memory Test; CVLT $=$ California Verbal Learning Test.

$* p<.05 . \quad * * p<.01 . \quad * * * p<.001$. 
specificity as assessed at admission obtained significantly better treatment results than those with reduced levels of memory specificity. Because scores for memory specificity did not change during the 7-month follow-up period, the authors suggested that autobiographical memory specificity possibly bears the quality of a trait marker. Subsequent studies have confirmed that in subjects with dysphoria (Mackinger et al., 2004; Mackinger, Loschin, \& Leibetseder, 2000; Svaldi \& Mackinger, 2003) and outpatients with depression (Dalgleish, Spinks, Yiend, \& Kuyken, 2001; Peeters, Wessel, Merckelbach, \& Boon-Vermeeren, 2002) autobiographical memory predicts the course of depression after statistically controlling for initial depression levels (however, see Brewin, Reynolds, \& Tata, 1999, for contradictory data).

Findings on the valence of the stimulus words are less clear and in patients with depression both higher levels of overgeneral memories to positive cues (Brittlebank et al., 1993; Dalgleish et al., 2001) as well as reduced levels of specific memories to negative cues (Peeters et al., 2002) have been found to be predictive of recovery of depression. Up to now, these studies have shown that overgenerality in memory predicts persistence of an existing acute depression. By contrast, there are no studies in which autobiographical memory specificity was investigated as a possible marker for vulnerability to a new onset (relapse/recurrence) of depression in individuals who formerly had depression. Recent findings (Raes, Hermans, de Decker, Eelen, \& Williams, 2003) suggest that for some people, overgenerality in memory may serve an affect regulation function and so may be adaptive in these individuals.

Although memory specificity seems to be a relatively stable retrieval style, specific psychological interventions have been found to modify this cognitive style. Williams, Teasdale, Segal, and Soulsby (2000) found that mindfulness-based cognitive therapy reduced the recall of categorical memories in patients in remission from depression. No equivalent change was found in the treatment as usual group. Because these preliminary findings suggest that psychological interventions can reduce overgeneral memories, there is a need for further studies into which psychological interventions are suitable to enhance specific memory retrieval and modify this possible marker of vulnerability for onset, persistence, and recurrence of depression.

In summary, the main purposes of the prospective part of the present study were (a) to assess the effect of additional group cognitive therapy on memory specificity in comparison with treatment as usual and (b) to investigate whether memory specificity predicts relapse/recurrence.

\section{Method}

\section{Participants}

See Part 1 for a more complete description of the recruitment of participants. Of the 172 randomly assigned participants who started treatment as usual or additional group cognitive therapy (Bockting et al., 2005), data on autobiographical memory at pretreatment were available for 116 participants (67.4\%). There were no significant differences in demographic and clinical characteristics or dependent measures at baseline among participants included in the present study $(n=116)$ and participants in the original sample but not included in the present study $(n=56)$, neither were there any differences among participants in one of the two conditions of the present study and participants in the same condition of the original sample but not included in the present study (all $p$ values $>.10$ ).

\section{Measures}

From the assessment battery used in the original study, the following measures were selected for outcome assessment in the present study.

Relapse/recurrence. To assess relapse/recurrence the SCID-I (First et al., 1997) was used. At baseline and at three follow-up assessments (3, 12, and 24 months), current and past depressive episodes were checked by interviewers (psychologist/research assistants) blind to treatment condition. All interviews were audiotaped. Two independent experienced psychiatrists who were blind to treatment condition evaluated all occasions of participants meeting the $D S M-I V$ criteria for major depression. In cases of disagreement, the $D S M-I V$ ratings of the psychiatrists were used for further analyses. The kappa for interrater agreement between the interviewers and psychiatrist on categorization of a relapse/recurrence or no relapse/recurrence was .96 , indicating high agreement.

In addition to relapse/recurrence as a primary outcome measure, the mean severity of all relapses (as assessed by the SCID-I: light, $<6$ symptoms; moderate, 6-7 symptoms; severe, $8-9$ symptoms), the number of relapses/recurrences, and the duration of the depressive episodes during the follow-up period were used as secondary outcome measures. To account for differences in follow-up time the observed number of times a patient had a relapse or the observed duration of the depressive episodes were also converted to number of relapses or weeks of depressive episodes, respectively, per 2 years at risk. Moreover, it can be argued that the pretreatment measurement of remission is randomly located in the time period of remission, resulting in an unreliable measurement of time in remission. Therefore, retrospective data on time in remission at baseline and prospective data were combined by also computing the total number of months in remission from the last depressive episode onward.

Severity of depressive symptoms. Scores on the 17-item HRSD (Hamilton, 1960) and the 21-item BDI (Beck et al., 1979) at baseline and the three follow-up assessments were used to analyze the trajectory of depressive symptoms.

AMT. A parallel version of the AMT different from the version at baseline was administered at 3 months of follow-up (a complete list of the cue words, instructions, and procedure are available from the first author).

\section{Procedure}

With random permutated blocks by use of computer-generated cards stored as concealed assignment codes in consecutively sealed envelopes under the responsibility of an independent research associate, patients were randomly assigned to (a) treatment as usual (TAU), or (b) TAU + group cognitive therapy (CT). Randomization was stratified by study location and the type of aftercare (family doctor, psychiatric center, or no aftercare). The $\mathrm{CT}$ in the experimental condition involved eight weekly 2-h group sessions. Each CT session followed a fixed structure, with agenda setting, review of homework, explanation of rationale of each session, and assignment of homework. The CT started with identification of negative thoughts (Session 1) and dysfunctional attitudes, (Sessions 1-3) and then proceeded to target change (Sessions 3-7) of these attitudes using different cognitive techniques such as Socratic questioning and identification of positive attitudes. Moreover, patients were encouraged to practice with alternative attitudes (Sessions 6-8). In addition, patients were asked to keep a diary of positive experiences to enhance specific memories of positive experiences instead of overgeneral memories (Sessions 4-6). Further specific relapse/recurrence prevention strategies were formulated in the last three sessions. TAU involved "naturalistic" care, that is, standard treatment, as typically provided by the referring agencies, or no aftercare at all.

\section{Results}

Using a preliminary Cox regression analysis to examine whether the effect of additional group CT was moderated by either of the stratification variables used in randomization, no effect of site or 
type of aftercare on relapse/recurrence over 24 months was found. Further analyses without these stratifying variables showed that adding $\mathrm{CT}$ to TAU resulted in a significant increasing protective effect with an increasing number of previous depressive episodes experienced. For patients with five or more previous episodes (41\% of the sample), CT significantly reduced relapse/recurrence from $71 \%$ to $46 \%$ (see Bockting et al., 2005, for a more detailed description of the efficacy results of the trial).

\section{Effect of Group CT on Proportion of Specific Memories}

First, we investigated whether there were any statistically significant differences for demographic and clinical characteristics or HRSD, BDI, or AMT scores between subjects allocated to CT $(n=60)$ or TAU $(n=56)$. No statistically significant differences were observed (all $p$ values $>.10$ ). Of special note is the nonsignificant difference in the number of specific memories at pretreatment, $F(1,114)=.001, p=.989$. Of the 60 subjects in the CT condition, only $5(9.3 \%)$ attended fewer than five sessions. In analyzing whether treatment or number of previous depressive episodes was related to memory specificity and whether there was a different response pattern to positive and negative cue words, a $2 \times 2 \times 2$ mixed-model analysis of variance was conducted with Treatment (CT or TAU) and Previous Episodes (less than five or five or more) as between-subjects variables and Cue Type (positive or negative) as a within-subjects variable. ${ }^{2}$ This analysis could be performed for the 101 patients for which post-treatment AMT scores were available $(n=57$ in the CT condition and $n=44$ in the TAU condition). The main effect of treatment was not significant, $F(1,97)=0.049, p=.82$. The same held true for the interaction effect of Treatment $\times$ Cue Type, of Treatment $\times$ Previous Episodes, and of Treatment $\times$ Cue Type $\times$ Previous Episodes. The effect size (Cohen's $d$ ) for the difference in number of specific memories at post-treatment between the CT and TAU conditions was negligible $(d=0.03)$. These results indicate that additional group CT did not differentially affect memory specificity.

\section{Autobiographical Memory as a Predictor of Relapse/Recurrence}

Because additional group CT did not seem to influence memory specificity, the predictive value of memory specificity on relapse/ recurrence was investigated in the total sample using a proportional hazard approach to survival analysis (Cox regression) with relapse/recurrence as the dependent variable and scores for memory specificity as independent variables.

Over the total study period of 24 months the cumulative rate for relapse/recurrence in our sample rose to $61.2 \%$. A Cox regression analysis was conducted by analyzing the number of positive and negative specific memories at baseline as predictor variables. Time to relapse was the duration of the euthymic period from entry into the study. This analysis did not reveal a significant effect for the number of positive specific memories, Wald $(1)=0.030, p=$ .863 , hazard ratio $=0.928,95 \%$ confidence interval $[\mathrm{CI}]=$ $0.397-2.167$, or number of negative memories, Wald $(1)=0.265$, $p=.607$, hazard ratio $=1.280,95 \% \mathrm{CI}=0.500-3.282$. After the number of previous episodes was also included in the model, only this variable proved to be predictive of relapse/recurrence, Wald $(1)=5.948, p=.015$, hazard ratio $=1.353,95 \% \mathrm{CI}=1.061-$
1.726. The number of specific memories in patients with no relapse/recurrence was $5.4(S D=2.8)$ versus $5.2(S D=2.7)$ in patients with a relapse/recurrence.

Because autobiographical memory impairment was associated with global cognitive impairment in the present study sample (see Part 1 above), using Cox regression analysis we also investigated whether any of the neuropsychological variables (i.e., immediate and delayed recall on the RBMT and CVLT, focused attention on the Stroop Color-Word Test, immediate memory for abstract digits (Digit Span: Forwards), and working memory (Digit Span: Backwards) predicted time to relapse. None of these variables proved to be predictive of relapse/recurrence (all $p$ values $>.10$ ), suggesting that cognitive impairments as observed in our sample of patients in remission did not constitute a risk factor for relapse/recurrence.

The relationship of AMT scores at pretreatment with secondary outcome measures (i.e., time of remittance from the last episode onward, the number of relapses/recurrences [per 2 years at risk], the mean severity of all relapses, and the total duration of the depressive episodes during the follow-up period [per 2 years at risk]) were analyzed with Pearson correlation coefficients. As can be seen in Table 4, none of the correlations of memory specificity scores with secondary outcome measures was statistically significant.

Next, we investigated whether the number of specific positive and negative autobiographical memories predicted the trajectory of depression scores by conducting mixed-effects growth curve modeling using the multilevel analysis software package MLwiN 1.10 (Rasbach et al., 2004). In analyzing the repeated measurements on the BDI from baseline $(M=11.8 ; S D=7.5)$ to $3(M=10.3$; $S D=7.3), 12(M=8.4 ; S D=6.8)$, and 24 months of follow-up $(M=7.8 ; S D=7.1)$, a quadratic model with random intercepts and fixed linear and quadratic terms best fitted the data. Addition of the number of specific positive or negative memories as predictors to the model did not yield significant effects $(z=-1.40$, $p=.0808$, and $z=0.29, p=.6141$, respectively), indicating that these variables were not able to explain the variance between respondents in baseline BDI measurements. Cross-level interactions for the number of positive and negative memories with the linear and quadratic time variables were also added to the model, but none of those appeared to be significant either. Hence, both predictor variables have no influence on the average growth trajectory.

In analysis of the repeated measurements on the HDRS from baseline $(M=3.6 ; S D=2.8)$ to the second $(M=5.5 ; S D=5.7)$, third $(M=4.8 ; S D=4.1)$, and fourth measurements $(M=5.1$; $S D=4.3$ ), a very similar quadratic model emerged. Again, adding the number of positive $(z=-0.85, p=.1977)$ or negative memories $(z=0.17, p=.5675)$ to the model as predictors did not result in significant effects. Addition of the cross-level interactions for the number of positive and negative memories with the linear and quadratic time variables produced no significant effects either. Thus, both predictor variables also have no influence on the average growth trajectory.

\footnotetext{
${ }^{2}$ Because a parallel version of the AMT different from the version at baseline was used at post-treatment, and no data on the equivalence of these different versions are available the effect of Time was not further analyzed.
} 
Table 4

Clinical Outcome Measures and Pearson's Correlation Coefficients With Number of Specific Memories on the AMT at Pretreatment $(n=116)$

\begin{tabular}{lccccc}
\hline \multicolumn{1}{c}{ Variable } & $M$ & $S D$ & $\begin{array}{c}\text { Specific } \\
\text { memories }(r)\end{array}$ & $\begin{array}{c}\text { Specific positive } \\
\text { memories }(r)\end{array}$ & $\begin{array}{c}\text { Specific negative } \\
\text { memories }(r)\end{array}$ \\
\hline $\begin{array}{l}\text { Time of remittance from last episode } \\
\quad \text { onwards (months) }\end{array}$ & 23.4 & 12.0 & .01 & .03 & -.02 \\
$\begin{array}{l}\text { Number of relapses } \\
\quad \text { Unadjusted values }\end{array}$ & 0.9 & 1.0 & .01 & -.02 & .03 \\
$\quad \begin{array}{l}\text { Converted values } \\
\text { a }\end{array}$ & 1.0 & 1.0 & .10 & .09 & .10 \\
$\begin{array}{l}\text { Duration depressive episodes during } \\
\quad \text { follow-up (weeks) }\end{array}$ & & & & -.08 & .03 \\
$\quad \begin{array}{l}\text { Unadjusted values } \\
\quad \text { Converted values }\end{array}$ & 9.4 & 13.2 & -.03 & -.02 & .03 \\
Mean severity of all relapses & 9.7 & 13.4 & .01 & -.03 & .04 \\
\hline
\end{tabular}

Note. $\quad$ AMT $=$ Autobiographical Memory Test.

${ }^{a}$ Values converted to number of relapses respectively weeks of depressive episodes per 2 years at risk.

To check whether the pattern of results was confounded by the fact that about half of the patients had received group CT in addition to TAU, these analyses were repeated separately for the two conditions. The results in both groups were very similar with none of the correlations of measures for memory specificity with primary or secondary outcome measures reaching the level of significance.

\section{Discussion}

The prospective part of this study had two aims. The first aim was to test the hypothesis that group CT would have a differential effect on memory specificity in comparison with TAU. No evidence for differential treatment effects was found. This result was unexpected, because during the group training patients were explicitly asked to keep a diary of positive experiences to enhance retrieval of specific memories of positive experiences instead of overgeneral memories. Because compliance with homework instructions for diary keeping from Sessions 4 to 6 was not verified, one possible explanation for this negative finding is that this treatment target was not reached because of noncompliance with homework instructions. Another possible explanation is that the effect of simply instructing participants to retrieve specific positive experiences is limited because participants do not know how to achieve this goal. A training to notice elements of subjective experience in a nonjudgmental way such as that provided in mindfulness-based CT (Williams et al., 2000) may be necessary to modify this retrieval process. The supposition that it is necessary to provide subjects with an internal strategy is also consistent with the results of experimental studies showing that the tendency to recall categorical memories can be altered by brief experimental manipulations such as decentering (Watkins, Teasdale, \& Williams, 2000) or reducing analytical self-focus (Watkins \& Teasdale, 2001). Simply giving homework instructions may promote verbal-analytical thinking and insufficiently stimulate a more experiential mode of processing, which may play a critical role in reducing the tendency toward an overgeneral retrieval style.

The second aim was to test the hypothesis that memory specificity would predict relapse/recurrence, because previous studies had focused only on the persistence of a depressive episode. This hypothesis was not supported for this main outcome measure (i.e., time to relapse from entry into the study) nor for secondary outcome measures, such as time of remission from the last episode onward, the number of relapses/recurrences, the mean severity of all relapses, the duration of all relapses, or the course of depressive symptoms during the follow-up period.

What explains this pattern of data? It could be argued that lack of memory specificity is not a deficit related to depression ("deficit model"), but that lowered memory specificity may also constitute a functional strategy by preventing individuals from recalling events that might evoke painful, negative emotions (Hermans et al., 2004; Raes et al., 2003). On the basis of such a functional model, it could be hypothesized that lack of specificity may buffer against the stress of daily hassles or recent life events and prolong the period of remission. With this perspective, being less specific may be advantageous in the euthymic phase and maladaptive in the long term during a depressive episode (e.g., because lack of memory specificity impedes adequate problem solving; Pollock \& Williams, 2001). In the present study, however, memory specificity was unrelated to the duration of remission from entry into the study and the last episode onward. Thus, no evidence supporting either a deficit or a more functional model of memory specificity was found. These findings cannot be attributed to a lack of statistical power or a restriction of range in scores on relevant variables, because our rather large well-defined patient sample showed reduced levels of memory specificity and also constituted a group vulnerable for relapse/recurrence, given the fact that during the 2-year follow-up period the cumulative rate for relapse/recurrence increased to $62 \%$. An alternative hypothesis to account for the present data is that reduced memory specificity constitutes one of the persistent cognitive deficits after recovery from depression and consequently its role in predicting relapse/recurrence may be more limited than previously assumed. However, in the absence of prospective studies on memory specificity as a premorbid vulnerability of individuals at higher risk for depression, this hypothesis awaits further study.

\section{General Discussion}

The study reported here is the first to our knowledge (a) to examine in a group of euthymic patients with a history of recurrent depression the association of autobiographical memory impair- 
ment with various clinical risk factors and neuropsychological measures in a comprehensive way and (b) to investigate the predictive value of autobiographical memory impairment for relapse /recurrence. The study results suggest that patients in remission are characterized by reduced levels of memory specificity. This memory impairment, however, does not appear to be related to clinical risk factors for relapse/recurrence and is also not predictive of relapse/recurrence in this vulnerable patient group. Memory specificity is associated with age, education level, and measures for immediate and delayed memory recall. Taken together, these data suggest that autobiographical memory specificity does not play a role in contributing to relapse/recurrence. These findings also call into question the clinical utility of trying to enhance autobiographical memory specificity in patients in remission with the purpose of preventing relapse/recurrence. Although mindfulness-based cognitive therapy (Williams et al., 2000) seems to be able to enhance memory specificity, it remains to be established whether this change actually mediates the preventive effect of this group therapy on relapse/recurrence.

Reduced memory specificity, however, does not have to be specific for depression. In the last two decades, the retrieval of overgeneral autobiographical memories on a cue-word task has also been found in individuals with posttraumatic stress disorder (McNally et al., 1995), acute stress disorder (Harvey, Bryant, \& Dang, 1998), and eating disorder (Dalgleish et al., 2003). A characteristic common to all of these clinical groups is the presence of clinically elevated levels of depression and/or a history of traumatic events. Moreover, memory impairments in general are also observed in other psychiatric disorders (Burt et al., 1995). Memory impairment might be associated with more overarching factors common to various forms of psychopathology (e.g., severity of illness, motivational deficits, or effortful processing deficits) (Dalgleish \& Watts, 1990). In depression and posttraumatic stress disorder in particular, deficits in executive functioning are prominent. Executive functioning refers to cognitive processes that control and integrate other cognitive activities such as episodic and autobiographical memory. As has already been noted by Williams (1995), executive dysfunction may be one of the pathways leading to overgeneral memory retrieval. Further more comprehensive studies into executive functioning in relation to episodic and autobiographical memory impairments in different diagnostic groups seem worthwhile as executive dysfunction may be one of the components contributing to memory specificity that has been overlooked in previous studies.

There are at least two reasons to think that the current data merit serious consideration. First, patients with recurrent depression in a euthymic phase form a rather unique group to study cognitive processes unaffected by severity of symptomatology or presence of psychiatric disorder. As a consequence, the present findings from a large, well-defined, and homogenous group of patients with recurrent remissions shed light on cognitive processes in patients in remission and seem to indicate that autobiographical memory impairment is characteristic for patients with a history of one or more previous depressive episodes. Second, by using a prospective design, it was possible to study the predictive value of less specific memories for the course of the disorder during a clinically relevant follow-up period of 24 months. This design substantiates our conclusion that the predictive value of less specific memories for relapse/recurrence is notably absent.
Finally, at least three limitations of this study merit consideration. First, we used the AMT version of McNally et al. (1995), in which subjects attempt to retrieve specific personal memories exemplifying trait adjectives having either positive (e.g., friendly or helpful) or negative valence (e.g., guilty or hostile) relevant for self-representations in traumatized individuals. Although these cues also seem relevant to the self-representation of patients who previously had depression, more research of the differential effects of different AMT cues in various clinical groups is needed. Moreover, it seems worthwhile to supplement memory cue-word tasks such as the AMT with procedures to try to capture the occurrence and quality of more spontaneous autobiographical memories as typically found in depression and posttraumatic stress disorder (Brewin, 1998). Second, in the present study patients with only one prior depressive episode and/or those who have been euthymic for more than 2 years were excluded. It may be possible that patients with two or more episodes constitute a group that may be etiologicaly different from those with only one previous depressive episode. In previous studies of preventive interventions in recurrent depression, evidence for etiologically different subgroups of patients differing in the number of previous depressive episodes has been found, although the number of previous depressive episodes demarcating distinct subgroups varies among studies (Bockting et al., in press; Ma \& Teasdale, 2004; Teasdale et al., 2000). Third, our research design does not allow us to conclude that memory specificity is a trait marker for vulnerability to the first onset of depression, because we did not study memory specificity in a group of patients without a history of depression before the first onset of depression (Just, Abramson, \& Alloy, 2001). In a recent analogue study after controlling for baseline levels of depression, negative life events were associated with increased depressive symptoms only in those students high in overgeneral memories at baseline (Gibbs \& Rude, 2004). Possibly memory specificity does not predict more autonomous recurrences of depression but will predict onset of depression in response to life events consistent with its moderating role in determining problemsolving reactions (Williams, Barnhofer, Crane, \& Beck, 2005). These considerations underline the necessity to conduct a prospective study in which the assessment of autobiographical memory precedes the onset of a first depressive episode.

\section{References}

American Psychiatric Association. (1994). Diagnostic and statistical manual of mental disorders (4th ed.). Washington, DC: Author.

Arntz, A., Meeren, M., \& Wessel, I. (2002). No evidence for overgeneral memories in borderline personality disorder. Behaviour Research and Therapy, 40, 1063-1068.

Beck, A. T., Rush, A. J., Shaw, B. F., \& Emery, G. (1979). Cognitive therapy of depression. New York: Guilford Press.

Bockting, C. L. H., Schene, A. H., Spinhoven, P., Koeter, M. W. J., Wouters, L. F., Huyser, J., et al. (2005). Preventing relapse/recurrence in recurrent depression with cognitive group therapy: A randomized controlled trial. Journal of Consulting and Clinical Psychology, 73, 647657.

Brewin, C. R. (1998). Intrusive autobiographical memories in depression and post- traumatic stress disorder. Applied Cognitive Psychology, 12, 359-370.

Brewin, C. R., Reynolds, M., \& Tata, P. (1999). Autobiographical memory processes and the course of depression. Journal of Abnormal Psychology, 108, 511-517.

Brittlebank, A. D., Scott, J., Williams, J. M. G., \& Ferrier, I. N. (1993). 
Autobiographical memory in depression: State or trait marker. British Journal of Psychiatry, 162, 118-121.

Burt, D. B., Zembar, M. J., \& Niederehe, G. (1995). Depression and memory impairment: A meta-analysis of the association, its pattern and specificity. Psychological Bulletin, 117, 285-305.

Dalgleish, T., Spinks, H., Yiend, J., \& Kuyken, W. (2001). Autobiographical memory style in seasonal affective disorder and its relationship to future symptom remission. Journal of Abnormal Psychology, 110, 335340.

Dalgleish, T., Tchanturia, K., Serpell, L., Hems, S., Yiend, J., de Silva, P. et al. (2003). Self-reported parental abuse relates to autobiographical memory style in patients with eating disorders. Emotion, 3, 211-222.

Dalgleish, T., \& Watts, F. N. (1990). Biases of attention and memory in disorders of anxiety and depression. Clinical Psychology Review, 10, 589-604.

de Decker, A., Hermans, D., Raes, F., \& Eelen, P. (2003). Autobiographical memory specificity and trauma in inpatient adolescents. Journal of Clinical Child and Adolescent Psychology, 32, 22-31.

Delis, D. C., Kramer, J. H., Kaplan, E., \& Ober, B. A. (1987). California verbal learning test: Adult version. San Antonio, TX: Psychological Corporation.

First, M. B., Spitzer, R. L., Gibbon, M., \& Williams, J. B. W. (1997). Structured clinical interview for DSM-IV axis I disorders (SCID-I/P). New York: New York State Psychiatric Institute, Biometrics Research Department.

Gibbs, B. R., \& Rude, S. S. (2004). Overgeneral autobiographical memory as depression vulnerability. Cognitive Therapy and Research, 28, 511526

Goddard, L., Dritschel, B., \& Burton, A. (1996). Role of autobiographical memory in social problem solving and depression. Journal of Abnormal Psychology, 105, 609-616.

Hamilton, M. (1960). A rating scale for depression. Journal of Neurology, Neurosurgery and Psychiatry, 23, 56-62.

Hammes, J. G. W. (1978). De Stroop Kleurwoord Test: Handleiding. Lisse, the Netherlands: Swets \& Zeitlinger.

Harvey, A. G., Bryant, R. A., \& Dang, S. T. (1998). Autobiographical memory in acute stress disorder. Journal of Consulting and Clinical Psychology, 66, 500-506.

Hermans, D., Van den Broeck, K., Belis, G., Raes, F., Pieters, G., \& Eelen, P. (2004). Trauma and autobiographical memory specificity in depressed inpatients. Behaviour Research and Therapy, 42, 775-789.

Just, N., Abramson, L. Y., \& Alloy, L. B. (2001). Remitted depression studies as tests of the cognitive vulnerability hypotheses of depression onset: A critique and conceptual analysis. Clinical Psychology Review, 21, 63-83.

Kremers, I. P., Spinhoven, P., \& Van der Does, A. J. W. (2004). Autobiographical memory in depressed and non-depressed patients with borderline personality disorder. British Journal of Clinical Psychology, 43, $17-29$.

Lezak, M. D., Howieson, D. B., \& Lorin, D. W. (2004). Neuropsychological assessment (4th ed.). Oxford: Oxford University Press.

Ma, S. H., \& Teasdale, J. D. (2004). Mindfulness-based cognitive therapy for depression: Replication and exploration of differential relapse prevention effects. Journal of Consulting and Clinical Psychology, 72, $31-40$.

Mackinger, H. F., Leibetseder, M. F., Kunz-Dorfer, A. A., Fartacek, R. R., Whitworth, A. B., \& Feldinger, F. F. (2004). Autobiographical memory predicts the course of depression during detoxification therapy in alcohol dependent men. Journal of Affective Disorders, 78, 61-65.

Mackinger, H. F., Loschin, G. G., \& Leibetseder, M. M. (2000). Prediction of postnatal affective changes by autobiographical memories. European Psychologist, 5, 52-61.

Mackinger, H. F., Pachinger, M. M., Leibetseder, M. M., \& Fartacek, R. R. (2000). Autobiographical memories in women remitted from major depression. Journal of Abnormal Psychology, 109, 331-334.
McNally, R. J., Lasko, N. B., Macklin, M. L., \& Pitman, R. K. (1995) Autobiographical memory disturbance in combat-related posttraumatic stress disorder. Behaviour Research and Therapy, 33, 619-630.

Nandrino, J. L., Pezard, L., Poste, A., Reveillere, C., \& Beaune, D. (2002). Autobiographical memory in major depression: A comparison between first-episode and recurrent patients. Psychopathology, 35, 335-340.

Ormel, J., Oldehinkel, A. J., \& Vollebergh, W. (2004). Vulnerability before, during, and after a major depressive episode: A 3-wave population-based study. Archives of General Psychiatry, 61, 990-996.

Paradiso, S., Lamberty, G. J., Garvey, M. J., \& Robinson, R. G. (1997). Cognitive impairment in the euthymic phase of chronic unipolar depression. Journal of Nervous and Mental Disease, 185, 748-754.

Park, R. J., Goodyer, I. M., \& Teasdale, J. D. (2002). Categoric overgeneral autobiographical memory in adolescents with major depressive disorder. Psychological Medicine, 32, 267-276.

Peeters, F., Wessel, I., Merckelbach, H., \& Boon-Vermeeren, M. (2002). Autobiographical memory specificity and the course of major depressive disorder. Comprehensive Psychiatry, 43, 344-350.

Phillips, S., \& Williams, J. M. G. (1997). Cognitive impairment, depression and the specificity of autobiographical memory in the elderly. British Journal of Clinical Psychology, 36, 341-347.

Pollock, L. R., \& Williams, J. M. G. (2001). Effective problem solving in suicide attempters depends on specific autobiographical recall. Suicide and Life-Threatening Behavior, 31, 386-396.

Raes, F., Hermans, D., de Decker, A., Eelen, P., \& Williams, J. M. G. (2003). Autobiographical memory specificity and affect regulation: An experimental approach. Emotion, 3, 201-206.

Rasbach, J., Steele, F., Browne, W., \& Prosser, B. (2004). A user's guide to MLwiN. London: Centre for Multilevel Modeling, Institute of Education, University of London.

Sampson, M. J., Kinderman, P., Watts, S., \& Sembi, S. (2003). Psychopathology and autobiographical memory in stroke and non- stroke hospitalized patients. International Journal of Geriatric Psychiatry, 18, 23-32.

Sheehan, D. V., Lecrubier, Y., Harnett-Sheehan, K., Amorim, P., Janavs, J., Weiller, E., et al. (1998). The MINI-International Neuropsychiatric Interview (M.I.N.I.): The development and validation of a structured diagnostic psychiatric interview for DSM-IV and ICD-10. Journal of Clinical Psychiatry, 59, 22-33.

Squire, L. R. (1995). Biological foundations of accuracy and inaccuracy in memory. In D. L. Schacter (Ed.), Memory distortions: How minds, brains, and societies reconstruct the past (pp. 197-225). Cambridge, MA: Harvard University Press.

Svaldi, J. J., \& Mackinger, H. F. (2003). Obstructive sleep apnea syndrome: Autobiographical memory predicts the course of depressive affect after nCPAP therapy. Scandinavian Journal of Psychology, 44, 31-37.

Teasdale, J. D., Segal, Z. V., Williams, J. M. G., Ridgeway, V. A., Soulsby, J. M., \& Lau, M. A. (2000). Prevention of relapse/recurrence in major depression by mindfulness-based cognitive therapy. Journal of Consulting and Clinical Psychology, 68, 615-623.

Tulving, E. (1972). Episodic and semantic memory. In E. Tulving \& W Donaldson (Eds.), Organization of memory (pp. 381-403). New York: Academic Press.

van Vreeswijk, M. F., \& de Wilde, E. J. (2004). Autobiographical memory specificity, psychopathology, depressed mood and the use of the Autobiographical Memory Test: A meta-analysis. Behaviour Research and Therapy, 42, 731-743.

Watkins, E., \& Teasdale, J. D. (2001). Rumination and overgeneral memory in depression: Effects of self-focus and analytic thinking. Journal of Abnormal Psychology, 110, 353-357.

Watkins, E., Teasdale, J. D., \& Williams, R. M. (2000). Decentring and distraction reduce overgeneral autobiographical memory in depression. Psychological Medicine, 30, 911-920. 
Wechsler, D. (1981). Manual for the Wechsler Adult Intelligence ScaleRevised. New York: Psychological Corporation.

Wessel, I., Meeren, M., Peeters, F., Arntz, A., \& Merckelbach, H. (2001). Correlates of autobiographical memory specificity: The role of depression, anxiety and childhood trauma. Behaviour Research and Therapy, 39, 409-421.

Wessel, I., Merckelbach, H., \& Dekkers, T. (2002). Autobiographical memory specificity, intrusive memory, and general memory skills in Dutch-Indonesian survivors of the World War II era. Journal of Traumatic Stress, 15, 227-234.

Wheeler, M. A., Stuss, D. T., \& Tulving, E. (1997). Toward a theory of episodic memory: The frontal lobes and autonoetic consciousness. Psychological Bulletin, 121, 331-354.

Williams, J. M. G. (1995). Depression and the specificity of autobiographical memory. In D. C. Rubin (Ed.), Remembering our past. Studies in autobiographical memory (pp. 244-267). Cambridge, MA: Cambridge University Press.

Williams, J. M. G., Barnhofer, T., Crane, C., \& Beck, A. T. (2005). Problem solving deteriorates following mood challenge in formerly depressed patients with a history of suicidal ideation. Journal of Abnormal Psychology, 114, 421-431.

Williams, J. M. G., \& Broadbent, K. (1986). Autobiographical memory in suicide attempters. Journal of Abnormal Psychology, 95, 144-149.

Williams, J. M. G., \& Dritschel, B. H. (1992). Categoric and extended autobiographical memories. In M. A. Conway, D. C. Rubin, H. Spinnler, \& W. Wagenaar (Eds.), Theoretical perspectives on autobiographical memory (pp. 391-410). Dordrecht, the Netherlands: Kluwer.

Williams, J. M. G., Ellis, N. C., Tyers, C., Healy, H., Rose, G., \& MacLeod, A. K. (1996). The specificity of autobiographical memory and imageability of the future. Memory \& Cognition, 24, 116-125.

Williams, J. M. G., Teasdale, J. D., Segal, Z. V., \& Soulsby, J. (2000). Mindfulness-based cognitive therapy reduces overgeneral autobiographical memory in formerly depressed patients. Journal of Abnormal Psychology, 109, 150-155.

Williams, W. H., Williams, J. M. G., \& Ghadiali, E. J. (1998). Autobiographical memory in traumatic brain injury: Neuropsychological and mood predictors of recall. Neuropsychological Rehabilitation, 8, 43-60.

Wilson, B., Cockburn, J., \& Baddeley, A. D. (1985). The Rivermead Behavioural Memory Test. Bury St. Edmunds, England: Thames Vally Test Corporation.

Winthorpe, C., \& Rabbitt, P. (1988). Working memory capacity, IQ, age, and the ability to recount autobiographical events. In M. M. Gruneberg, P. E. Morris, \& R. N. Sykes (Eds.), Practical aspects of memory: Current research and issues (pp. 175-179). Chichester, England: Wiley.

Received October 29, 2004

Revision received July 26, 2005

Accepted July 28, 2005 